Psychology

Psychology, Health \& Medicine

HEALTH

G

MEDICINE

ISSN: 1354-8506 (Print) 1465-3966 (Online) Journal homepage: https://www.tandfonline.com/loi/cphm20

\title{
The contribution of purpose in life to psychological morbidity and quality of life in chronic pain patients
}

\section{Valéria M. Almeida, Cátia Carvalho \& M. Graça Pereira}

To cite this article: Valéria M. Almeida, Cátia Carvalho \& M. Graça Pereira (2020) The contribution of purpose in life to psychological morbidity and quality of life in chronic pain patients. Psychology, Health \& Medicine, 25:2, 160-170, DOI: $10.1080 / 13548506.2019 .1665189$

To link to this article: https://doi.org/10.1080/13548506.2019.1665189

曲 Published online: 15 Sep 2019.

6 Submit your article to this journal

Џ Article views: 56

Q View related articles $\asymp$

View Crossmark data \lceil 


\title{
The contribution of purpose in life to psychological morbidity and quality of life in chronic pain patients
}

\author{
Valéria M. Almeida, Cátia Carvalho and M. Graça Pereira (D) \\ School of Psychology, University of Minho, Braga, Portugal
}

\begin{abstract}
Chronic pain is a cause of morbidity, interference with daily functioning, decreased health and quality of life. Purpose in life acts as a protective factor and mitigates these consequences. This crosssectional study aimed to determine whether purpose in life contributed to psychological morbidity and quality of life in patients with chronic pain by controlling psychological variables related to health (pain severity and interference, pain perceptions, pain catastrophizing and coping). The sample included 103 patients diagnosed with chronic pain. Results showed that purpose in life independently contributed to psychological morbidity and to mental quality of life, but not to physical quality of life, after controlling for pain-related variables. Results showed the relevance of purpose in life to identify patients at risk of developing psychological morbidity and decreased quality of life, suggestting the need to intervene in chronic pain, specifically on purpose in life, to prevent psychological morbidity and promote quality of life, in this population.
\end{abstract}

\section{ARTICLE HISTORY}

Received 16 September 2018

Accepted 15 July 2019

\section{KEYWORDS}

Purpose in life; psychological morbidity; quality of life; chronic pain

\section{Introduction}

Pain from a chronic condition is an indicator of injury and a toxic influence (Sturgeon \& Zautra, 2010). Chronic pain (CP) is persistent/recurrent, lasting for more than 3-6 months (Treede et al., 2015). The most frequent sites are the lumbar and cervical regions, legs, knees, arms, and hip, and the most common etiology is osteoarthritis, osteoarthrosis, disc herniation, osteoporosis, spinal disorders, and trauma (Azevedo, Costa-Pereira, Mendonça, Dias, \& Castro-Lopes, 2012).

Breivik, Collett, Ventafridda, Cohen, and Gallacher (2006) found a prevalence of moderate to severe CP in $19 \%$ of 46.394 participants. CP is associated with socio demographic factors, namely, being female (Tsang et al., 2008; Van Hecke, Torrance, \& Smith, 2013), being elderly (Azevedo et al., 2012; Tsang et al., 2008; Van Hecke et al., 2013), belonging to a low socioeconomic status, and being in an inactive work status (Van Hecke et al., 2013). In Portugal, CP prevalence is $36.7 \%$, being higher among the elderly, retired, unemployed, and those with less education (Azevedo et al., 2012).

Pain experience is multimodal affecting different health and well-being domains (Sturgeon \& Zautra, 2010), associated with a decreased quality of life (QoL) (Nolet,

CONTACT M. Graça Pereira gracep@psi.uminho.pt E School of Psychology, University of Minho, Campus de Gualtar, Braga 4710-057, Portugal 
Kristman, Cote, Carroll, \& Cassidy, 2014). Pain's high prevalence emphasizes the need for research and implementation of interventions focused on pain management (Azevedo et al., 2012).

CP causes emotional distress, depression (Gerrits, van Oppon, van Marwijk, Penninx, \& van der Horst, 2014; West, Stewart, Foster, \& Usher, 2012), mental exhaustion, anxiety, fatigue, and catastrophizing (West et al., 2012). In Azevedo et al. (2012), 13\% of individuals with CP presented a diagnosis of depression, while in the Kroenke et al. (2013) study, approximately half presented one or more anxiety disorders with a negative impact on healthrelated QoL. Psychological distress in patients with CP was significantly higher compared to healthy individuals (Gormsen, Rosenberg, Bach, \& Jensen, 2010). In adulthood, CP is a serious health problem that affects patients' well-being, with severe personal, interpersonal, and economic consequences (O’Brien \& Breivik, 2012; Tsang et al., 2008). However, some patients are not affected due to personal resources that increase the likelihood of resilience, showing a relevant personal resource, such as the belief that a person's life has meaning and purpose (Sturgeon \& Zautra, 2010). Nevertheless, this has not been as deeply studied in the health area as other positive psychological variables (Goodin et al., 2013; Hood, Pulvers, Carrillo, Merchant, \& Thomas, 2012).

Global meaning is a central component of the framework model of meaning in the context of stress and coping (Vehling et al., 2011) encompassing core beliefs, personal goals, and subjective perceptions of coherence and purpose (Park, 2010). Crumbaugh and Maholick (1964) defined 'purpose in life' (PL) as the ontological meaning of life from the point of view of the experiencing individual. McKnight and Kashdan (2009) argued that purpose provides a foundation allowing people to be more resilient to obstacles, stress, and tension, making it easier to face challenges knowing that a purpose exists.

$\mathrm{PL}$ is a strong predictor of adjustment in life and is associated with better health (Davison \& Jhangri, 2013; Kim, Sun, Park, Kubzansky, \& Peterson, 2013; Kraus, Rodrigues, \& Dixe, 2009; Sherman \& Simonton, 2012), greater socioeconomic status, being employed, and married (Pinquart, 2002). Associations between PL, psychological well-being, and low levels of depressive symptoms were found (Dezutter, Luyckx, \& Wachholtz, 2015; Pinquart, 2002), and PL has shown to predictr absence of depression, anxiety, and demoralization (Vehling et al., 2011). Even when controlling for other variables (e.g. optimism, pessimism, emotionality), PL remained associated to lower anxiety, depression, negative affect, and greater positive affect (Smith \& Zautra, 2004). An overall sense of purpose is an important protective factor in psychological distress (Sherman \& Simonton, 2012; Vehling et al., 2011). PL was considered a potential life-satisfaction promoter (Dezutter et al., 2015) in healthy people and cancer patients (Teques, Carrera, Ribeiro, Teques, \& Ramon, 2016). Low PL was associated with increased mortality in elderly populations (Boyle, Barnes, Buchman, \& Bennett, 2009), while higher PL was considered a protective factor against myocardial infarction in individuals with coronary heart disease (Kim et al., 2013), contributing to successful aging (Boyle et al., 2009). Individuals with greater PL are more proactive in their health care, with a higher probability of using preventive health services (Kim, Strecher, \& Ryff, 2014). Thus, PL has a positive relationship with coping and mental and physical QoL (Kraus et al., 2009). Moreover, higher PL results in greater tolerance to pain (Smith et al., 2009), and faster recovery time after surgery (Smith \& Zautra, 2004). However, in some studies, PL was not related to physical QoL (Sherman \& Simonton, 2012), although meaning in life emerges as an important factor of psychological adjustment to pain (Dezutter et al., 2015). Nevertheless, CP 
threatens the individuals' perception of their purpose (Dezutter et al., 2015), implying a review of life's goals and expectations (Pinquart, Silbereisen, \& Fröhlich, 2009).

Given the relevance of spirituality to psychology, and its relevance and benefits for people with pain, PL emerges as a part of pain assessment and management. Although there are some studies on PL and its relationship with psychological morbidity and QoL, literature on PL in the CP field is still scarce (Dezutter et al., 2015; Richardson \& Morley, 2017; Siddall, Lovell, \& MacLeod, 2015; Smith \& Zautra, 2004), namely on how PL contributes to psychological morbidity and QoL.

This study focuses on the widespread acknowledgment that life has a purpose and meaning (Sherman \& Simonton, 2012), and analyzes how PL contributes to psychological morbidity and physical and mental QoL in CP patients. Sociodemographic (age, education, work status, financial income), clinical (pain duration, comorbidities, pain severity), and psychological variables (pain interference, illness perceptions, pain catastrophizing, illnessfocused coping, wellness-focused coping) were the control variables, associated with psychological morbidity and QoL (Jorgensen, 2014; Sassen, 2018). Some other pain related variables of negative affect were not included, such as fear of pain or pain anxiety, since there seems to be construct redundancy on whether pain catastrophizing is conceptually different from these other variables. Therefore, choice was made to use pain catastrophizing as it is one of the most robust psychological predictors of psychological distress and depression symptoms (Burri, Ogata, Rice, \& Williams, 2018; Turk \& Okifuji, 2002; van der Have et al., 2015). It was hypothesized that PL will be related to psychological morbidity and physical and mental QoL, after controlling for sociodemographic, clinical, and psychological variables related to pain.

\section{Materials and methods}

This was a cross-sectional study with a correlational design.

\section{Participants and procedures}

The study included 103 patients diagnosed with CP in a main hospital in the North of Portugal. The inclusion criteria were: 1 ) receiving treatment at the Chronic Pain Unit of the Hospital, 2) being able to read and write,and 3) being over 18 years old. Patients diagnosed with severe psychiatric disorders (psychosis) or cognitive deficit registered in their clinical chart were excluded. The study was approved by the Ethics Committee of the Hospital. Participants (Table 1) were contacted by their physician at the pain consultation, and were informed regarding the objectives and procedures of the study, their confidentiality rights and voluntary participation. All participants signed an informed consent.

\section{Measures}

To measure PL, the PL Test Revised (PIL-R, Harlow, Newcomb \& Bentler, 1987) was used. The instrument evaluates objectives, ambitions, and goals that inspire a sense of purpose in personal and existential life. The 20 items are answered on a 7-point Likert-type scale (1 - 
Table 1. Participants' characteristics.

\begin{tabular}{llll}
\hline Characteristics & $N$ & $\%$ & Mean (SD) \\
\hline Sex & 22 & 21.4 & \\
$\quad$ Men & 81 & 78.6 & $53.86(11.38)$ \\
$\quad$ Women & & & \\
Age & & & \\
Relationship status & 25 & 24.3 & 7.01 (3.53) \\
$\quad$ Without partner & 78 & 75.7 & \\
$\quad$ With partner & & & \\
Education (years) & & & \\
Work status & 76 & 73.8 & 48 (86.2) \\
$\quad$ Inactive & 27 & 26.2 & \\
$\quad$ Active & & & \\
Monthly income & 56 & 45.6 & \\
$\quad>€ 500$ & 47 & 54.4 & \\
$\quad$ <500 & & & \\
Pain duration (months) & & & \\
Presence of comorbidities & & 41.7 & \\
$\quad$ Without comorbidities & 43 & 58.3 & \\
$\quad$ With comorbidities & 60 & 14.6 & \\
Pain medication use & & 85.4 & \\
$\quad$ No medication use & 15 & & \\
$\quad$ Medication use & 88 &
\end{tabular}

strongly disagree to 7 - totally agree). High results indicate more PL. The Cronbach's alpha, in this study, was .75 for the total scale.

To measure pain severity and pain interference, the Brief Pain Inventory (BPI; Cleeland, 1991) was used. The instrument evaluates pain severity and degree of pain interference on a $0-10$ Likert-type scale. Higher results indicate greater severity and functional interference. In this study, the Cronbach's alpha for the severity subscale was .73 , and for the interference subscale was .80 .

To measure illness perceptions, the Brief Illness Perception Questionnaire (Brief IPQ; Broadbent, Petrie, Main, \& Weinman, 2006) was used. It assesses illness cognitive and emotional representations through 9 items evaluated on a $0-10$ scale, except for item 9 (causes). Higher results indicate more threatening illness perceptions. The Cronbach's alpha of the total scale, in this study was .72 .

To measure psychological morbidity, the Hospital Anxiety and Depression Scale (HADS; Zigmond \& Snaith, 1983) was used. It includes 14 items in two subscales: anxiety and depression. Higher scores correspond to higher psychological morbidity. The overall result is an indicator of psychological distress. In this study, the Cronbach's alpha for the total scale was .85 .

To measure pain catastrophizing, the Pain Catastrophizing Scale (PCS; Sullivan et al., 1995) was used. The instrument includes 13 items describing thoughts, perceptions, and catastrophic feelings associated with pain, using a $0-4$ rating scale to evaluate their frequency. Higher scores indicate higher levels of catastrophizing. The Cronbach's alpha for the total scale, in this study, was .93.

To measure coping strategies in chronic pain, the Chronic Pain Coping Inventory-42 (CPCI; Jensen et al., 1995) was used. The instrument evaluates cognitive and behavioral coping. It consists of 42 items evaluated on a 1-7 scale. The strategies listed fit into illnessfocused coping or wellness-focused coping. Higher scores indicate greater use of coping 
strategies. In this study, the Cronbach's alpha for illness-focused coping was .82, and for wellness-focused was .77.

To measure QoL, the Short Form Health Survey (SF-12v2; Ware, Kosinski, \& Keller, 1996) was used. The instrument includes 12 items evaluating physical and mental QoL. Higher scores in each dimension correspond to better QoL, respectively. The Cronbach's alpha, in this study, was .85 for physical QoL, and .84 for mental QoL.

\section{Statistical analysis}

The data were processed using IBM SPSS ${ }^{\varpi}$ version 24.0. The preliminary bivariate analysis evaluated relationships between study outcomes and demographic, clinical, and psychological control variables, using Pearson's correlation and Bisserial Point coefficient. Multiple hierarchical regression evaluated the relationship of PL with study outcomes, controlling for other measures. The hierarchical model for psychological morbidity included PL in block 1 , and in block 2, the variables pain severity, pain interference, illness perceptions, pain catastrophizing, illness-focused coping, and wellness-focused coping. The hierarchical model for physical QoL included in block 1 PL, and in block 2, the variables work status, pain severity, pain interference, illness perceptions, illness-focused coping, wellness-focused coping, and psychological morbidity. The hierarchical model for mental QoL included PL in block 1, and in block 2, the variables pain interference, illness perceptions, illness-focused coping, catastrophizing, and psychological morbidity.

\section{Results}

\section{Descriptive statistics}

Psychological morbidity was related to pain severity, pain interference, illness representations, pain catastrophizing, illness-focused coping, wellness-focused coping, and PL. Physical QoL was related to work status, pain severity, pain interference, illness perceptions, illness-focused coping, wellness-focused coping, psychological morbidity, and PL. Mental QoL was related to pain interference, illness perceptions, catastrophizing, illness-focused coping, psychological morbidity and PL. Besides, the correlation between PL and pain interference was negative (Table 2).

\section{Hierarchical regressions}

Contribution of PL to psychological morbidity after controlling for sociodemographic, clinical, and psychological variables related to pain

PL explained $46.7 \%$ of the total variance of psychological morbidity, with model 1 being significant $\left(R^{2} .467, F(1,101)=88.414, p<.001\right)$. Model 2 explained $62 \%$ of the total variance $\left(R^{2}\right.$ of $.620, F(7.95)=22.165, p<.001$, Adjusted $\left.R^{2}=.592\right)$. Higher PL $(\beta=-.332, t=-4.910, p<.001)$ was associated with lower levels of psychological morbidity after adjusting for control variables (Table 3 ). 


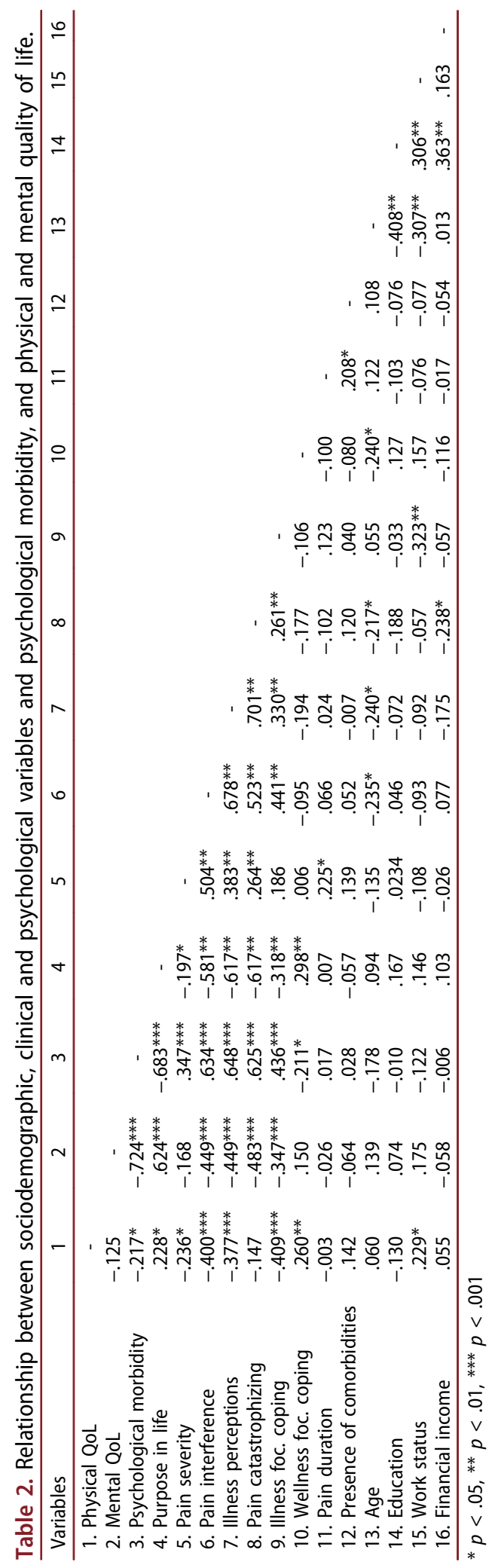


Table 3. Purpose in life contribution for psychological morbidity after controlling for sociodemographic, clinical, and psychological variables.

\begin{tabular}{|c|c|c|c|c|}
\hline \multicolumn{5}{|l|}{ Psychological Morbidity } \\
\hline \multirow[b]{2}{*}{ Variable } & \multicolumn{2}{|c|}{ Model 1} & \multicolumn{2}{|c|}{ Model 2} \\
\hline & $\beta$ & $t$ & $\beta$ & $t$ \\
\hline $\begin{array}{l}\text { Purpose in life } \\
\text { Pain severity }\end{array}$ & -.683 & $-9.403^{* * *}$ & $\begin{array}{l}-.332 \\
.082\end{array}$ & $\begin{array}{l}-3.595^{* * *} \\
1.102\end{array}$ \\
\hline Pain interference & & & .144 & 1.412 \\
\hline Illness perceptions & & & .124 & 1.174 \\
\hline Pain catastrophizing & & & 1.91 & $2.030^{*}$ \\
\hline Illness-focused coping & & & .159 & $2.241^{*}$ \\
\hline Wellness-focused coping & & & -.024 & -.359 \\
\hline$R^{2}$ & & .467 & & .620 \\
\hline$F$ & & $88.414^{* * *}$ & & $22.165^{* * *}$ \\
\hline$\Delta R^{2}$ & & .467 & & .153 \\
\hline$\Delta F$ & & 88.414 & & 6.398 \\
\hline
\end{tabular}

${ }^{*} p<.05,{ }^{* *} p<.01,{ }^{* * *} p<.001$

Table 4. Contribution of purpose in life to physical and mental quality of life after controlling for sociodemographic, clinical, and psychological variables.

\begin{tabular}{|c|c|c|c|c|c|c|c|c|}
\hline \multirow[b]{3}{*}{ Variables } & \multicolumn{4}{|c|}{ Physical Quality of Life } & \multicolumn{4}{|c|}{ Mental Quality of Life } \\
\hline & \multicolumn{2}{|c|}{ Model 1} & \multicolumn{2}{|c|}{ Model 2} & \multicolumn{2}{|c|}{ Model 1} & \multicolumn{2}{|c|}{ Model 2} \\
\hline & $\beta$ & $t$ & $\beta$ & $t$ & $\beta$ & $t$ & $\beta$ & $t$ \\
\hline Purpose in life & .228 & $2.352^{*}$ & -.085 & -.657 & .624 & $8.022^{* * * *}$ & .267 & $2.660^{* *}$ \\
\hline Work status & & & .086 & .940 & - & - & - & - \\
\hline Pain severity & & & -.053 & -.521 & - & - & - & - \\
\hline Pain interference & & & -.256 & -1.851 & & & -.047 & -.466 \\
\hline Illness perceptions & & & -.254 & -1.973 & & & .157 & 1.401 \\
\hline Pain catastrophizing & & & - & - & & & -.034 & -.333 \\
\hline Psychological morbidity & & & .252 & 1.880 & & & -.579 & $-5.337^{* * *}$ \\
\hline Illness-focused coping & & & -.287 & $-2.790^{* *}$ & & & -.032 & -.411 \\
\hline Wellness-focused coping & & & .221 & $2.460^{*}$ & - & - & - & - \\
\hline$R^{2}$ & & .052 & & .331 & & .389 & & .566 \\
\hline$F$ & & $5.530^{*}$ & & $5.812^{* * *}$ & & $64.356^{* * *}$ & & $20.845 * *$ \\
\hline$\Delta R^{2}$ & & .052 & & .240 & & .389 & & .177 \\
\hline$\Delta F$ & & 5.530 & & 5.600 & & 64.356 & & 7.806 \\
\hline
\end{tabular}

Contribution of PL to physical and mental QoL after controlling for sociodemographic, clinical, and psychological variables related to pain

PL explained $5.2 \%$ of the total variance of physical QoL, with model 1 being significant $\left(R^{2} .052, F(1,101)=5.530, p=.021\right.$, Adjusted $\left.R^{2}=.043\right)$. Model 2 explained $33.1 \%$ of the total variance $\left(R^{2}\right.$ of $.331, F(7,94)=5.812, p<.001$, Adjusted $\left.R^{2}=.274\right)$. PL $(\beta=-.085, t=-.657, p=.513)$ was not associated with physical QoL when other variables were entered (Table 4 ).

PL explained $38.9 \%$ of the total variance of mental QoL, with model 1 being significant $\left(R^{2} .389, F(1,101)=64,356, p<.001\right)$. Model 2 explained $56.6 \%$ of the total variance $\left(R^{2} .566, F(6,96)=20,845, p<.001\right.$, Adjusted $\left.R^{2}=.539\right)$. Greater PL $(\beta=.267, t=2.660, p=.009)$ was associated with better mental QoL after adjusting for control variables (Table 4$)$. 


\section{Discussion}

Results revealed that PL was negatively related to psychological morbidity. Previous studies suggest that PL is a protective factor against depression (Pinquart, 2002; Smith \& Zautra, 2004), since individuals with a strong purpose have fewer depressive symptoms (Dezutter et al., 2015; Siddall et al., 2015) and lower levels of anxiety (Leeson et al., 2015; Vehling et al., 2011).

PL showed a positive association with physical and mental QoL, which is in agreement with other studies (Davison \& Jhangri, 2013; Kim et al., 2013; Smith \& Zautra, 2004). McCracken, Vowles and Eccleston $(2004,2005)$ found that people's ability to reorient their lives and set new goals, despite the pain, was associated with better functioning. Sherman and Simonton (2012) analized PL using CP and non-pain populations, and found a stronger association between PL and psychological morbidity in $\mathrm{CP}$ population. In the face of a threatening event like $\mathrm{CP}$, being goal oriented and attaining goals despite pain and its interference, brings more satisfaction than achieving goals when adversity is not perceived.

Although no causality should be drawn from this cross-sectional study, PL contributed independently and negatively to psychological morbidity, corroborating the literature, suggesting that depression may be a consequence of lower levels of purpose (Dezutter et al., 2015; Smith \& Zautra, 2004). Maintaining or renewing a sense of purpose and meaning during illness represents a protective factor for depressive mood (Vehling et al., 2011): higher level of PL before transplants predicted lower depression (Leeson et al., 2015), and higher levels of purpose in patients who underwent knee replacement surgery predicted lower levels of anxiety (Smith \& Zautra, 2004). PL contributed significantly to lower psychological distress in patients receiving treatment in primary care, as well as in cancer patients (Sherman \& Simonton, 2012). However, in Vehling et al. study (2011), the global meaning in life was not a predictor of anxiety, in cancer patients.

PL contributed independently and positively to mental QoL, according to previous studies (Davison \& Jhangri, 2013; Kraus et al., 2009), since even when other variables such as optimism and emotionality are controlled, PL remains related to better mental QoL (Smith \& Zautra, 2004). Purpose has been shown to contribute to the maintenance of a good QoL, with evidence indicating associations between PL, psychological wellbeing and low levels of depressive symptoms (Dezutter et al., 2015). Psychological morbidity was found to partially mediate the relationship between disability and QoL in patients with chronic low back pain (Ferreira \& Pereira, 2014).

PL, in this study, did not contribute to physical QoL. This finding is in line with Sherman and Simonton (2012) results, where PL was not related to physical QoL in patients with cancer. Other studies reported that purpose may be more important for psychological adjustment than for physical functioning (Dezutter et al., 2015), although the literature is not consensual. In patients receiving primary health care, this association was significant (Sherman \& Simonton, 2012). Having a strong life purpose has resulted in increased pain tolerance (Smith et al., 2009), faster recovery after surgery (Smith \& Zautra, 2004), and acts as a protector against myocardial infarction in adults with coronary disease (Kim et al., 2013). Resilient individuals adopt coping strategies and are more willing to accept pain by reducing pain's control over their emotions (Sturgeon \& Zautra, 2010) and daily activities. Thus, it is possible that purpose contributes to physical QoL through coping, since it has a positive 
relationship with coping and mental and physical QoL (Kraus et al., 2009). The mediating role of coping is well established in the literature (Dardas \& Ahmad, 2015; Morasco et al., 2013).

The results of the present study suggest that PL contributed negatively to psychological morbidity and positively to mental QoL, after controlling for health-related psychological variables. The role of purpose seems pertinent to individuals who are dealing with significant medical conditions (Sherman \& Simonton, 2012). Interventions based on coping strategies focused on assigning meaning to pain and accommodating the pain experience in the individual's existential life perception bring significant gains to CP patients (Gruszczyńska \& Knoll, 2015; Park, 2010).

This study has limitations, such as the sample size, the instruments that were selfreport measures, and the cross-sectional design that does not allow causality. Future studies should include social support, and investigate the role of pain interference in PL due to the strong association between these variables. Having high purpose might mean that patients are affected less by their pain, carrying out activities and fulfilling their life goals.

\section{Disclosure statement}

No potential conflict of interest was reported by the authors.

\section{ORCID}

M. Graça Pereira (D) http://orcid.org/0000-0001-7987-2562

\section{References}

Azevedo, L. F., Costa-Pereira, A., Mendonça, L., Dias, C. C., \& Castro-Lopes, J. M. (2012). Epidemiology of chronic pain: A population-based nationwide study on its prevalence, characteristics and associated disability in Portugal. The Journal of Pain, 13(8), 773-783.

Boyle, P. A., Barnes, L. L., Buchman, A. S., \& Bennett, D. A. (2009). Purpose in life is associated with mortality among community dwelling older persons. Psychosomatic Medicine, 71(5), 574-579.

Breivik, H., Collett, B., Ventafridda, V., Cohen, R., \& Gallacher, D. (2006). Survey of chronic pain in Europe: Prevalence, impact on daily life, and treatment. European Journal of Pain, 10(4), 287-333.

Burri, A., Ogata, S., Rice, D., \& Williams, F. (2018). Pain catastrophizing, neuroticism, fear of pain, and anxiety: Defining the genetic and environmental factors in a sample of female twins. PLoS ONE, 13, 1-15.

Crumbaugh, J. C., \& Maholick, L. T. (1964). An experimental study in existentialism: The psychometric approach to Frankl's concept of noogenic neurosis. Journal of Clinical Psychology, 20(2), 200-207.

Dardas, L. A., \& Ahmad, M. M. (2015). Coping strategies as mediators and moderators between stress and quality of life among parents of children with autistic disorder. Stress and Health, 31(1), 5-12.

Davison, S. N., \& Jhangri, G. S. (2013). The relationship between spirituality, psychosocial adjustment to illness, and health-related quality of life in patients with advanced chronic kidney disease. Journal of Pain and Symptom Management, 45(2), 170-178.

Dezutter, J., Luyckx, K., \& Wachholtz, A. (2015). Meaning in life in chronic pain patients over time: Associations with pain experience and psychological well-being. Journal of Behavioral Medicine, 38(2), 384-396. 
Ferreira, M. S., \& Pereira, M. G. (2014). The mediator role of psychological morbidity in patients with chronic low back pain in differentiated treatments. Journal of Health Psychology, 19(9), 1197-1207.

Gerrits, M. M. J. G., van Oppon, P., van Marwijk, H. W. J., Penninx, B. W. J. H., \& van der Horst, H. E. (2014). Pain and the onset of depressive and anxiety disorders. Pain, 155, 53-59.

Goodin, B. R., Glover, T. L., Sotolongo, A., King, C. D., Sibille, K. T., Herbert, M. S., \& Fillingim, R. B. (2013). The association of greater dispositional optimism with less endogenous pain facilitation is indirectly transmitted through lower levels of pain catastrophizing. The Journal of Pain, 14(2), 126-135.

Gormsen, L., Rosenberg, R., Bach, F. W., \& Jensen, T. S. (2010). Depression, anxiety, health-related quality of life and pain in patients with chronic fibromyalgia and neuropathic pain. European Journal of Pain, 14(2), 127.e1-127.e8.

Gruszczyńska, E., \& Knoll, N. (2015). Meaning-focused coping, pain, and affect: A diary study of hospitalized women with rheumatoid arthritis. Quality of Life Research, 24(12), 2873-2883.

Hood, A., Pulvers, K., Carrillo, J., Merchant, G., \& Thomas, M. D. (2012). Positive traits linked to less pain through lower pain catastrophizing. Personality and Individual Differences, 52(3), 401-405.

Jorgensen, B. (2014). Change in illness perception to improve quality of life for chronic pain patients. School of physician assistant studies. Retrieved from https://commons.pacificu.edu/pa/477/

Kim, E. S., Strecher, V. J., \& Ryff, C. D. (2014). Purpose in life and use of preventive health care services. Proceedings of the National Academy of Sciences, 111(46), 16331-16336.

Kim, E. S., Sun, J. K., Park, N., Kubzansky, L. D., \& Peterson, C. (2013). Purpose in life and reduced risk of myocardial infarction among older U.S. adults with coronary heart disease: A two-year follow-up. Journal of Behavioral Medicine, 36(2), 124-133.

Kraus, T., Rodrigues, M., \& Dixe, A. (2009). Sentido de vida, saúde e desenvolvimento humano Meaning of life, health and human development. Referência, 2(10), 77-88. Retrieved from http://www.index-f.com/referencia/2009pdf/10-7788.pdf

Kroenke, K., Outcalt, S., Krebs, E., Bair, M. J., Wu, J., Chumbler, N., \& Yu, Z. (2013). Association between anxiety, health-related quality of life and functional impairment in primary care patients with chronic pain. General Hospital Psychiatry, 35(4), 359-365.

Leeson, L. A., Nelson, A. M., Rathouz, P. J., Juckett, M. B., Coe, C. L., Caes, E. W., \& Costanzo, E. S. (2015). Spirituality and the recovery of quality of life following hematopoietic stem cell transplantation. Health Psychology, 34(9), 920-928.

McCracken, L. M., Vowles, K. E., \& Eccleston, C. (2004). Acceptance of chronic pain: Component analysis and a revised assessment method. Pain, 107(1-2), 159-166.

McCracken, L. M., Vowles, K. E., \& Eccleston, C. (2005). Acceptance-based treatment for persons with complex, long standing chronic pain: A preliminary analysis of treatment outcome in comparison to a waiting phase. Behaviour Research and Therapy, 43(10), 1335-1346.

McKnight, P. E., \& Kashdan, T. B. (2009). Purpose in life as a system that creates and sustains health and well-Being: An integrative, testable theory. Review of General Psychology, 13(3), 242-251.

Morasco, B. J., Lovejoy, T. I., Lu, M., Turk, D. C., Lewis, L., \& Dobscha, S. K. (2013). The relationship between PTSD and chronic pain: Mediating role of coping strategies and depression. Pain, 154(4), 609-616.

Nolet, P. S., Kristman, V. L., Cote, P., Carroll, L. J., \& Cassidy, J. D. (2014). Is low back pain associated with worse health-related quality of life 6 months later? European Spine Journal, 24 (3), 458-466.

O'Brien, T., \& Breivik, H. (2012). The impact of chronic pain-European patients' perspective over 12 months. Scandinavian Journal of Pain, 3(1), 23-29.

Park, C. L. (2010). Making sense of the meaning literature: An integrative review of meaning making and its effects on adjustment to stressful life events. Psychological Bulletin, 136(2), 257-301.

Pinquart, M. (2002). Creating and maintaining purpose in life in old age : A meta-analysis. Ageing International, 27(2), 90-114.

Pinquart, M., Silbereisen, R. K., \& Fröhlich, C. (2009). Life goals and purpose in life in cancer patients. Supportive Care in Cancer, 17(3), 253-259. 
Richardson, H., \& Morley, S. (2017). Action identification and meaning in life in chronic pain. Scandinavian Journal of Pain, 9(1), 1-10.

Sassen, B. (2018). Health, health indicators, and public health. In B. Sassen (Ed.), Nursing: Health education and improving patient self-management (pp. 1-23). Cham: Springer. doi:10.1007/ 978-3-319-51769-8_1

Sherman, A. C., \& Simonton, S. (2012). Effects of personal meaning among patients in primary and specialized care: Associations with psychosocial and physical outcomes. Psychology and Health, 27(4), 475-490.

Siddall, P. J., Lovell, M., \& MacLeod, R. (2015). Spirituality: What is its role in pain medicine? Pain Medicine, 16(1), 51-60.

Smith, B. W., Tooley, E. M., Montague, E. Q., Robinson, A. E., Cosper, C. J., \& Mullins, P. G. (2009). The role of resilience and purpose in life in habituation to heat and cold pain. The Journal of Pain, 10(5), 493-500.

Smith, B. W., \& Zautra, A. J. (2004). The role of purpose in life in recovery from knee surgery. International Journal of Behavioral Medicine, 11(4), 197-202.

Sturgeon, J. A., \& Zautra, A. J. (2010). Resilience: A new paradigm for adaptation to chronic pain. Current Pain and Headache Reports, 14(2), 105-112.

Teques, A. P., Carrera, G. B., Ribeiro, J. P., Teques, P., \& Ramon, G. L. (2016). The importance of emotional intelligence and meaning in life in psycho-oncology. Psycho-Oncology, 25(3), 324-331.

Treede, R. D., Rief, W., Barke, A., Aziz, Q., Bennett, M. I., Benoliel, R., ... Wang, S. (2015). A classification of chronic pain for ICD-11. PAIN, 156(6), 1-7.

Tsang, A., Von Korff, M., Lee, S., Alonso, J., Karam, E., Angermeyer, M. C., ... Watanabe, M. (2008). Common chronic pain conditions in developed and developing countries: Gender and age differences and comorbidity with depression-anxiety disorders. Journal of Pain, 9(10), 883-891.

Turk, D., \& Okifuji, A. (2002). Psychological factors in chronic pain: Evolution and revolution. Journal of Consulting and Clinical Psychology, 70, 678-690.

van der Have, M., Brakenhoff, L. K. P. M., van Erp, S. J. H., Kaptein, A. A., Leenders, M., Scharloo, M., ... Fidder, H. H. (2015). Back/joint pain, illness perceptions and coping are important predictors of quality of life and work productivity in patients with inflammatory bowel disease: A 12-month longitudinal study. Journal of Crohn's \& Colitis, 9(3), 276-283.

Van Hecke, O., Torrance, N., \& Smith, B. H. (2013). Chronic pain epidemiology and its clinical relevance. British Journal of Anaesthesia, 111(1), 13-18.

Vehling, S., Lehmann, C., Oechsle, K., Bokemeyer, C., Krüll, A., Koch, U., \& Mehnert, A. (2011). Global meaning and meaning-related life attitudes: Exploring their role in predicting depression, anxiety, and demoralization in cancer patients. Supportive Care in Cancer, 19(4), 513-520.

West, C., Stewart, L., Foster, K., \& Usher, K. (2012). The meaning of resilience to persons living with chronic pain: An interpretive qualitative inquiry. Journal of Clinical Nursing, 21(9-10), 1284-1292. 